\title{
Articles
}

\section{Receipt Through Repetition}

\section{Tim Greer}

Vivian Bussinguer S. Andrade

Jeff Butterfield

Agnes Mischinger

\section{Kobe University}

One of the ways that people show they are listening is by repeating part of what the prior speaker just said. This practice allows listeners to establish recipiency in a way that is specific, providing the speaker with moment-by-moment feedback on the recipient's understanding as well as giving a "go-ahead" signal. This paper uses Conversation Analysis (CA) to explore the interactional practice of repetition as recipiency. The data are taken from video recordings of L2 users of English in paired and small group discussions. The analysis provides suggestions for how this practice can help encourage language learning in conversation settings.

相手が言ったことの一部を繰り返すことは相手の言っていることを聴いているということを示 す方法の一つである。相手の発話を繰り返すことにより聞き手は自分が相手の言うことを理解し ており、それを承認している、さらに続けられたしということを刻々とフィードバックしていること になるのである。このようにして聞き手は相手の言うことを受容(recipiency)することになるわけ である。本研究は会話分析 (Conversational Analysis)を分析方法として使用し、繰り返しによる 受容 (receipt through repetition)の構造を明らかにする。英語学習者がグループ活動を行ってい る際の会話をビデオに録画したものをデータとして使用した。会話での繰り返しが話し手と聞き 手相互の共通理解を生みだし、言語学習をサポートする経過が明らかにされた。

Keywords: recipiency, repetition, conversation analysis, interaction, novice talk, L2 pragmatics

JALT Journal, Vol. 31, No. 1, May, 2009 


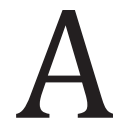
s language teachers, we are constantly observing students speaking in their second language. Intuitively we know when they are succeeding and when they are having trouble, or when they seem to be doing something in a way that is different from the way that a 'native speaker' might do it. However, it is often difficult to spell out just what such things are.

With its participant-centered focus on naturally occurring interaction, Conversation Analysis (CA) is one methodological approach that is currently receiving increasing interest among applied linguists as a means of documenting how novice speakers accomplish various social actions in their second language (most notably, Firth and Wagner, 1997; Gardner \& Wagner, 2004; Markee \& Kasper, 2004; Richards and Seedhouse, 2005; Schegloff, Koshik, Jacoby, \& Olsher, 2002; Seedhouse, 2005; Wagner and Firth, 2007). Just as natural sciences like astronomy or geology are built on empirical descriptions of natural phenomena, so too does CA aim to provide a detailed descriptive account of an ordinary observable occurrence: interaction. CA generally gathers its evidence from how speakers act and react to the turn-by-turn sequential development of mundane and institutional conversations (Schegloff, 1996a). Using video and audio recordings, CA researchers develop a case by gathering collections of similar interactional phenomena and describing them from the micro-socio-perspective of the participants themselves.

In the current study we examine video-recorded interactional data between Japanese learners of English during speaking tests. We initially noticed that the participants often repeated words, either within their own turn or as a re-doing of some element of the prior speaker's turn. By paying careful attention to the sequential contexts in which these repetitions were employed, we found that, despite their limited ability, the novice learners used next-turn repetition in much the same ways as relative experts, such as English native speakers: ${ }^{1}$ to initiate repair, ${ }^{2}$ to agree, and to claim comprehension of the topic at hand. The last of these is the focus of the current paper: receipt through repetition.

\section{CA Research into Receipt Markers and Repetition}

We will begin by reviewing previous socio-interactional research into receipt and repetition. By receipt we are referring to those minimal turns at talk which demonstrate that a person is listening. Such 'reactive tokens' do not stop the primary speaker from talking, and do not in themselves claim the floor (Clancy, Thompson, Suzuki \& Tao. 1996, p. 356). Tokens that 
most regularly accomplish this sort of action in English include yeah, $\mathrm{mm}$, uhuh and I see, and in Japanese un, hai, and ohn. They have been identified in the literature under a variety of terms, including accompaniment signals (Kendon, 1967), backchannels (Yngve, 1970), and aizuchi (Maynard, 1989). While much of the existing research, including CA studies (Jefferson, 1985, 1993; Gardner 1997, 2001), focuses on L1 interaction, some preliminary research has been conducted on receipt tokens among second language learners. Gardner (1998), for example, looked at how learners vocalize their understanding by using the acknowledgement token 'mm.'

While such tokens are by far the most common way to do receipt, they are not the only means speakers have of demonstrating understanding. In fact there are a number of related-but slightly different-practices that interactants use to do receipt (Schegloff, 1982). Utterances like wow or good for example, offer some assessment of the prior turn (Goodwin, 1986); or the change-of-state token 'oh' makes a claim that the recipient has undergone an epistemological transition-from 'not-knowing' to 'now-knowing' (Heritage, 1984; Schegloff, 2007). The fact that these forms of receipt change the way the primary-speaker produces the remainder of the ongoing talk is evidence to suggest that not all receipt tokens accomplish listenership in the same way. While fascinating, these recipiency practices will remain largely beyond the scope of the present study.

The receipt practice in which we are interested here involves repeating some element of the primary-speaker's turn. Schegloff (1996b) notes that such receipts are produced with downward intonation, and are often followed by agreement, acknowledgement, or confirmation tokens, such as in excerpt 1.

Excerpt 1: Kanagawa (Receipt-through-repetition)

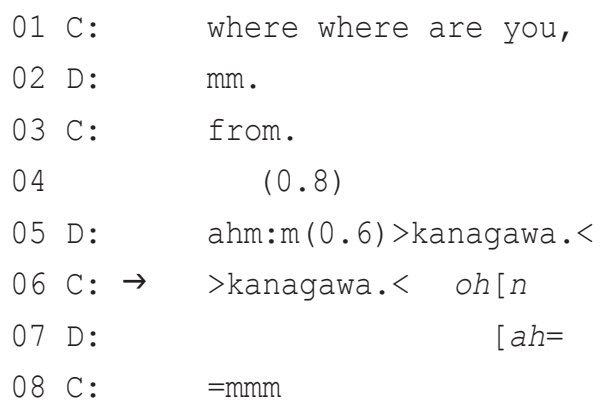


In line 6 of this excerpt, C provides receipt of D's prior turn by repeating the key element with falling intonation, and following it immediately with an acknowledgement token in Japanese. D then treats the repeat as responseworthy (Schegloff, 1996b) by doing confirmation in line 7. Accomplishing listenership can happen this way in most languages, but Clancy et al. (1996) found that repetitions were used as reactive tokens almost twice as often in Japanese as in English, making it probable that Japanese learners of English, like those in the present study, will tend to over-rely on this interactional practice.

The practice of other-repetition as receipt has been studied from a CA approach by Svennevig (2004), who found that the recipient could use nextturn repetition to make public a variety of inner cognitive states, including claims to hearing and understanding, or to express an emotional stance in regard to the prior speaker's turn. It is this focus on outwardly observable, real-time claims to otherwise inaccessible 'in-the-head' states that makes CA invaluable for investigating language learning as a socioculturally accomplished process (Wagner and Firth, 2007). Svennevig's data was collected from institutional talk between expert and novice speakers of Norwegian, and will inform the current study, which focuses only on novice speakers of English.

However, just as not all receipts are done through repetition, neither do all repetitions accomplish receipt. Next-turn other-repetitions are regularly used with upward intonation to seek confirmation or initiate repair, such as in the turns marked with an arrow in the following extracts.

Excerpt 2. Initiating a confirmation check

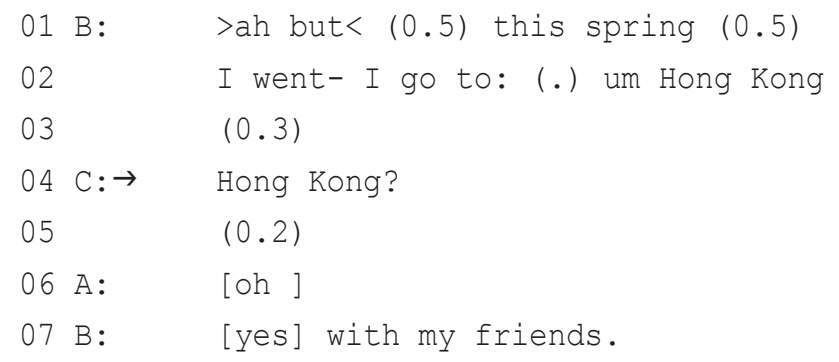

Excerpt 3. Next-turn repair initiation through repetition
01 A:
um: : a:nd umm (0.7) in Otaru,
02
they er there are many (0.4) slope. 


$\begin{array}{ll}03 & (0.4) \\ 04 \text { D } \rightarrow \quad & \text { slope? } \\ 05 & (0.8) \\ 06 \text { D: } & \text { what slope? } \\ 07 & (0.7) \\ 08 \text { A : } & >\text { s::aka. saka.< } \\ & \text { slope } \quad \text { slope }\end{array}$

Notice that when some element of the prior turn is repeated with rising intonation, as in these examples, the next-speaker hears it as some sort of sequence-initiating action and responds to it, whereas next-turn repetition like that in excerpt 1 closes an action sequence. In CA terms, the former is the first pair part of an adjacency pair (e.g., Question/Answer), while the latter is a sequence-closing third, since it acknowledges the second pair part of a just-prior adjacency pair (see Schegloff, 2007). In short, repetition delivered with upward intonation is doing the opposite of receipt: the listener is making a claim that the prior information is unknown, unrecognized, untrue, or in some other way problematic.

Repetition can also be used to accomplish agreement (Pomerantz, 1984):

Excerpt 4. Repetition as agreement

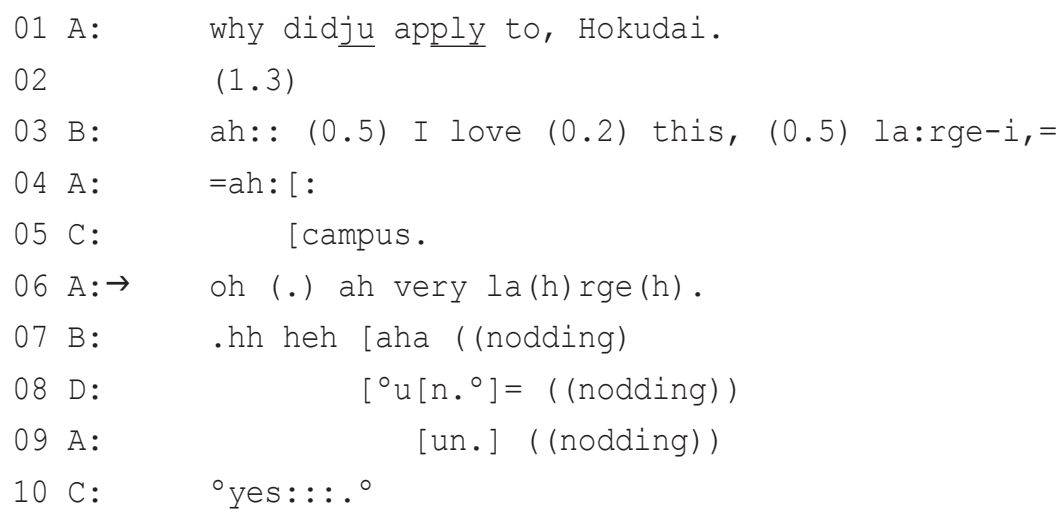

Here, in line 3 speaker B produces an assessment ('large'), which receives immediate acknowledgement from $A$ in next-turn and then, in line 6, an upgraded repetition of the assessment ('very large') and multiple agreement 
tokens and nods from the other recipients during the interaction that follows.

Another location where next-turn repetition was regularly found in our data was during confirmation in word search sequences, as shown in excerpt 5 .

Excerpt 5. Repetition as confirmation

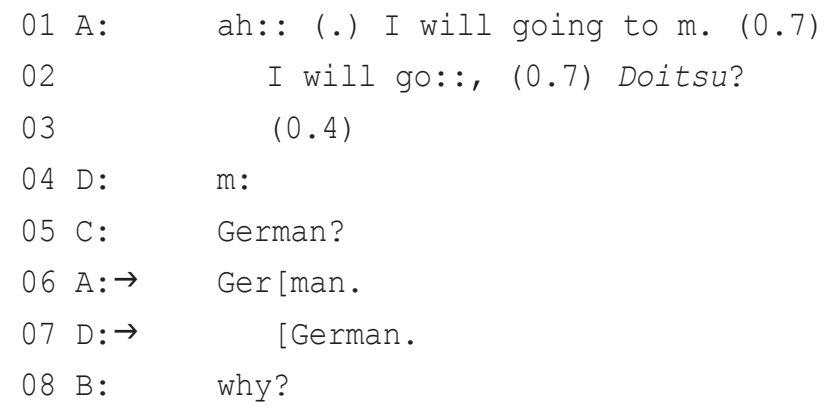

In these sorts of action sequences, a speaker designs the turn in such a way as to demonstrate that he or she is having trouble accessing some element of the turn-in-progress, in this case, the word "Germany." Evidence available to the recipients includes: delay-markers (such as 'ah::' and 'm.'), turn-internal pauses, same-turn repetition, and stretched vowel sounds ('go::'). ${ }^{3}$ All of these allow the speaker to delay completion of the turn while still maintaining the floor. When another participant offers a candidate repair, as $C$ does in line 6 , the word-searcher often confirms the candidate token by repeating it with falling intonation. ${ }^{4}$ This practice works in a similar way to what Schegloff (1996a; 1996b) has called "confirming allusions." Teachers likewise rely on repetition in the third turn of Initiation-Response-Feedback (IRF) sequences to display acceptance of a student answer to a teacher-initiated knowledge check question (Hellermann, 2003).

So what is clear is that repetition by another speaker in next-turn can accomplish a variety of socio-pragmatic functions. However for the remainder of this paper we are going to focus only on situations when repeating elements of the primary-speaker's prior turn demonstrates listenership, such as that shown in excerpt 1 . Given that up until now most studies have focused on repetition in L1 talk, the present study aims to look at some ways second language users claim receipt by redoing part of the prior turn. 


\section{Background and Data Set}

The data have been gathered from three series of oral proficiency tests video-recorded among Japanese learners of English. The participants were 1st- and 2nd-year university students from a variety of faculties who were undertaking weekly classes in oral English proficiency. The data sets are summarized in Table 1.

Table 1. The Data Set

\begin{tabular}{|l|c|c|c|l|}
\hline $\begin{array}{l}\text { Data } \\
\text { code }\end{array}$ & $\begin{array}{c}\text { Group } \\
\text { size }\end{array}$ & $\begin{array}{c}\text { Task } \\
\text { length }\end{array}$ & Recordings & Speaking task \\
\hline 4ninST & 4 & $\begin{array}{c}6 \\
\text { minutes }\end{array}$ & 10 & $\begin{array}{l}\text { Discuss a topic from } \\
\text { class, randomly selected } \\
\text { just prior to the test. }\end{array}$ \\
\hline Fnds & 2 & 5 & 8 & $\begin{array}{l}\text { Discuss an episode of } \\
\text { the sitcom "Friends," } \\
\text { which was shown in } \\
\text { class. }\end{array}$ \\
\hline TB & 2 & 4 & 8 & $\begin{array}{l}\text { Discuss a topic from } \\
\text { class, randomly selected } \\
\text { just prior to the test. }\end{array}$ \\
\hline
\end{tabular}

The video files were saved in MPEG format and, after repeated viewings, were transcribed according to the conventions devised by Jefferson (as documented in Schegloff, 2007 and summarized in Appendix 1). Through extensive consultation and careful observation, we gathered and analyzed a collection of 76 instances of interaction in which repetition accomplished acknowledgement/receipt. While this is a sizeable data set, the CA approach does not attempt to establish generalizability on the basis of frequency, but rather aims to undertake a deep descriptive account of the focal interactional practice. Paraphrasing Sacks (1984b:411), ten Have (1999) notes:

1. The ultimate 'results' of CA are a set of formulated 'rules' or 'principles,' which participants are demonstrably oriented to in the natural interactions.

2. The way to arrive at such results is to analyse singular instances, formulate rules, and 'test' these with comparable other instances ( $\mathrm{p}$. 135-136). 
Our purpose in this paper is to qualitatively explicate how the candidate phenomenon is achieved temporally and sequentially, and to consider what implications this might have for L2 pedagogy. Several key instances in which these learners achieved receipt through repetition are outlined below.

\section{Findings}

Receipt through repetition is an interactional practice that is part of a broader discourse pattern in which one speaker (A) is established as the teller and the other (B) as the recipient. The practice is regularly used in conjunction with other forms of minimal receipt token, including minimal "aizuchi-like" responses such as un, $m m$, ohn, or what Jefferson $(1985$, p. 4) has termed "passive recipiency." Speaker B uses repetition to signal to A that he/she understands a given element of the prior turn, and is actively following the general flow of the talk. In essence the practice is a way of displaying listenership that is more specific than just "uhuh" or "mm." The sequence of turns we will analyze can be summarized as follows:

Turn 1. A: produces an informing or telling, sometimes in a way that invites uptake

Turn 2. B: $\rightarrow$ provides receipt by repeating some element of the turn-in-progress

Turn 3. A: (may minimally acknowledge receipt such as by nodding, then) continues turn in progress, or adds a new turn increment

Some further examples of the interactional practice can be seen in the following excerpts:

Excerpt 6: 4ninST 9a Spring

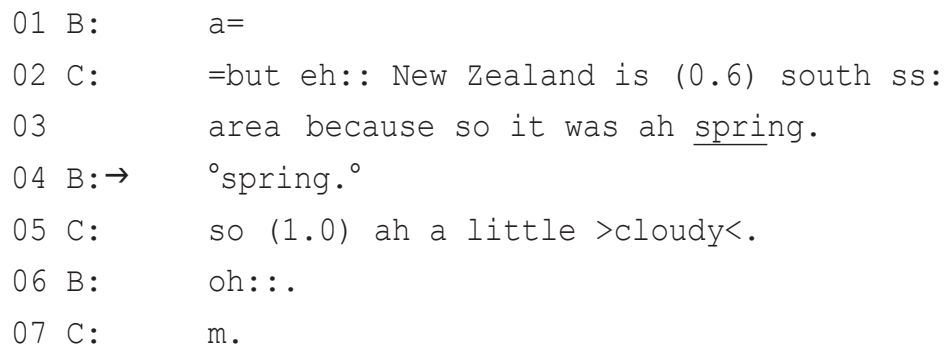




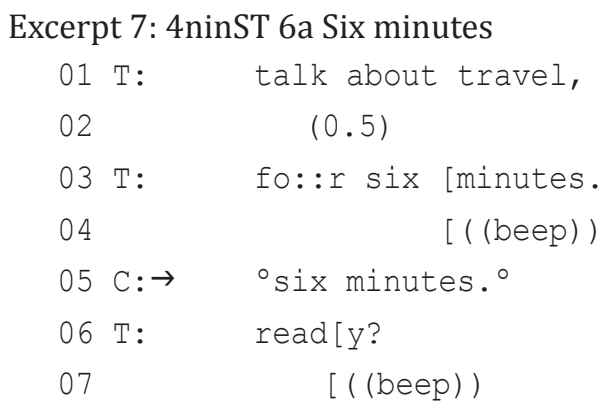

Excerpt 8: 4ninST 5a Hokkaido ${ }^{5}$

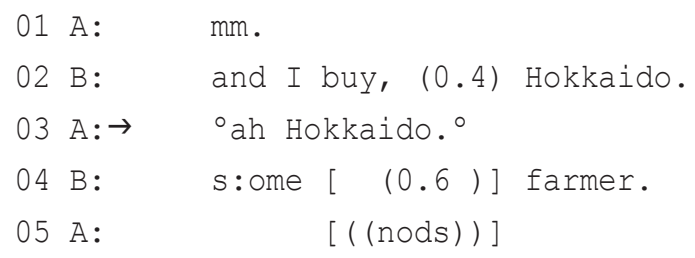

In each of these excerpts we can see that one speaker is mainly talking and the other is mainly listening. The recipients cast themselves in the role of listener when they repeat some element of the just-prior turn segment, indicated in the transcripts by an arrow. Note that in each of these cases, the repetition is delivered with falling intonation, differentiating it from the repair-initiator we saw in excerpt 3 , which was produced with rising intonation, leading the participants to treat it quite differently in the ongoing talk. Although by no means the rule, we found that the receipt-through-repetition turn was often done with lower volume, as depicted in the transcripts enclosed in ${ }^{\circ}$ degree $\operatorname{marks}{ }^{\circ}$, further indicating that the recipients see themselves as the non-primary speaker during the repeated portion of the talk.

In excerpt 7 , the turn prior to the repetition is incomplete, and the primary speaker goes on to continue speaking afterwards. This is further evidence to show that the interactants understand the repeater to be in the role of recipient, as the primary speaker goes on to complete the turn, often with minimal or no recognition of the recipient repetition.

At other times the receipt-through-repetition comes at a point where the primary speaker's turn has reached a point of possible completion. In these cases, the recipient often accompanies his or her next-turn repetition with one or more other acknowledgement tokens such as $a h, o h$, or yeah. 
As can be seen from the following examples, in these situations the primary speaker sometimes keeps talking by adding a further TCU (excerpt 9), but at other times receipt-through-repetition can also lead to a change in the primary speaker (excerpts 10 and 11). One associated feature of these action sequences is that the receipt-through-repetition is actually a third-turn action, where the first-turn is a question, the second-turn a response and the receipt completes the sequence, as shown in excerpt 9.

Excerpt 9: 4ninST 3a Kobe

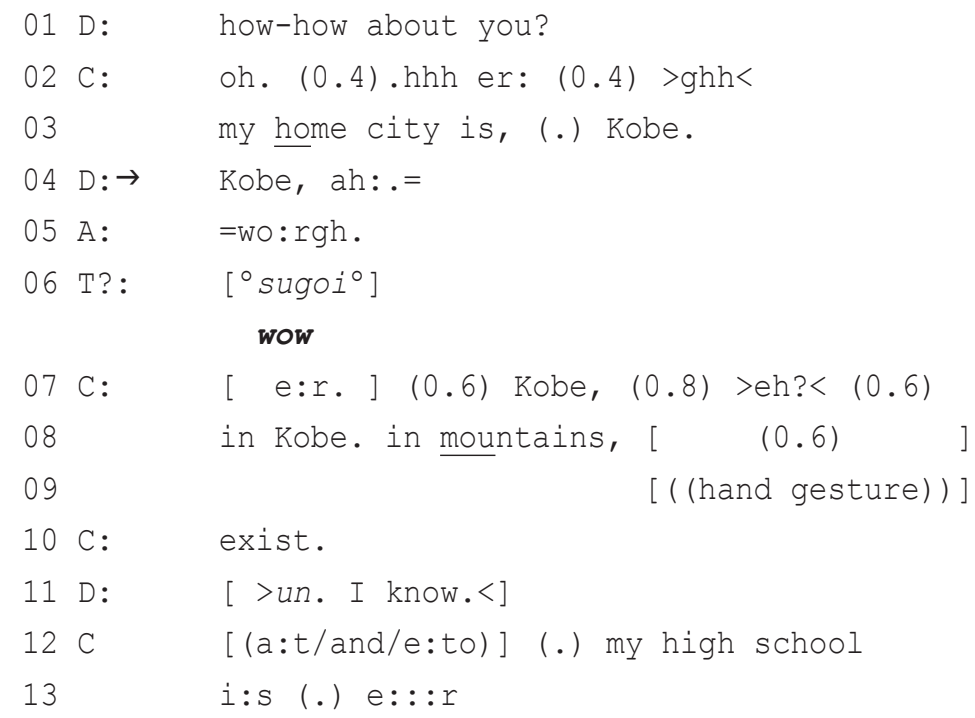

Excerpt 10: 4ninST 4a Trombone
$01 \mathrm{~A}:$
ah. I play trombone.
$02 \mathrm{~B}: \rightarrow$
[trombone e:h.
03 D:
[oh: : :
04 A:
. hehehah
05 D:
in my junior school junior high
06
school
(.) I play
(.) flute.

Excerpt 11: 4ninST 9a Singapore

01

(2.0) 


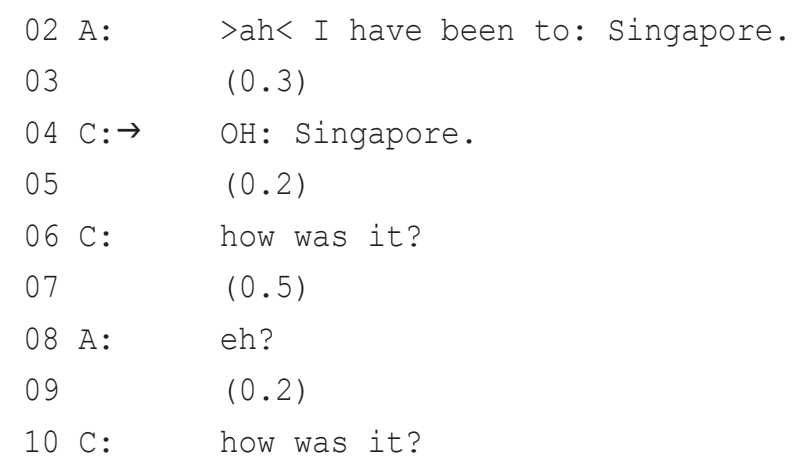

As can be seen from the analysis so far, the repeated turn-segment is usually short, and often consists of only one word. Moreover, participants do not repeat just any word. Svennevig (2004) typified the repeated turn segments as "discrete, detailed pieces of exact information" (p. 502). Almost invariably, the tokens have not appeared in the conversation up until that point and appear towards the end of the primary-speaker's turn. The part that gets repeated regularly consists of one or two short elements-particularly proper nouns. In fact, in roughly one third of the instances we analyzed the repeated element was a place name, such as Osaka or Singapore. In another third of the cases (36\%), the repeated element was a word or phrase that was somehow being negotiated in the interaction. This would suggest that receipt-through-repetition plays an important role in displaying the recipient's understanding of a specific term, especially one that is expected to play some role in the development of the topic in progress.

Note that in almost all of the examples so far the recipient repeats the key element smoothly in next-turn without any hesitation or gap. Research into this practice indicates that this is regularly the case with expert speakers (Schegloff, 1996a, 1996b; Svennevig, 2004). However, in the data we looked at the listener often left a slight gap before repeating the key element, as in line 3 of excerpt 11 . This delay may be attributed to the fact that the participants were novice speakers of English, and therefore required more time to formulate their responses (see Wong, 2000). However it may equally be a factor of the group dynamics. We noticed this tended to happen more when the students were talking in groups. In multi-party talk the issue of speaker selection becomes more complicated and such inter-turn silences may appear while participants consider which of the three listeners will voice the receipt. Naturally, this is not such an issue in paired conversations. 
The excerpts we have examined so far have all included some sort of "new" and therefore "newsworthy" element that gets acknowledged through repetition. Related to this we found that receipt-through-repetition was regularly used when the participants were negotiating meaning, such as when they needed to circumlocute or apply a novel meaning to some word.

Consider the following excerpt, in which the participants have been discussing whether or not they believe life exists on other planets. Speaker A is listing the sort of countries where he thinks UFO sightings are likely to occur.

Excerpt 12: TB8 USA

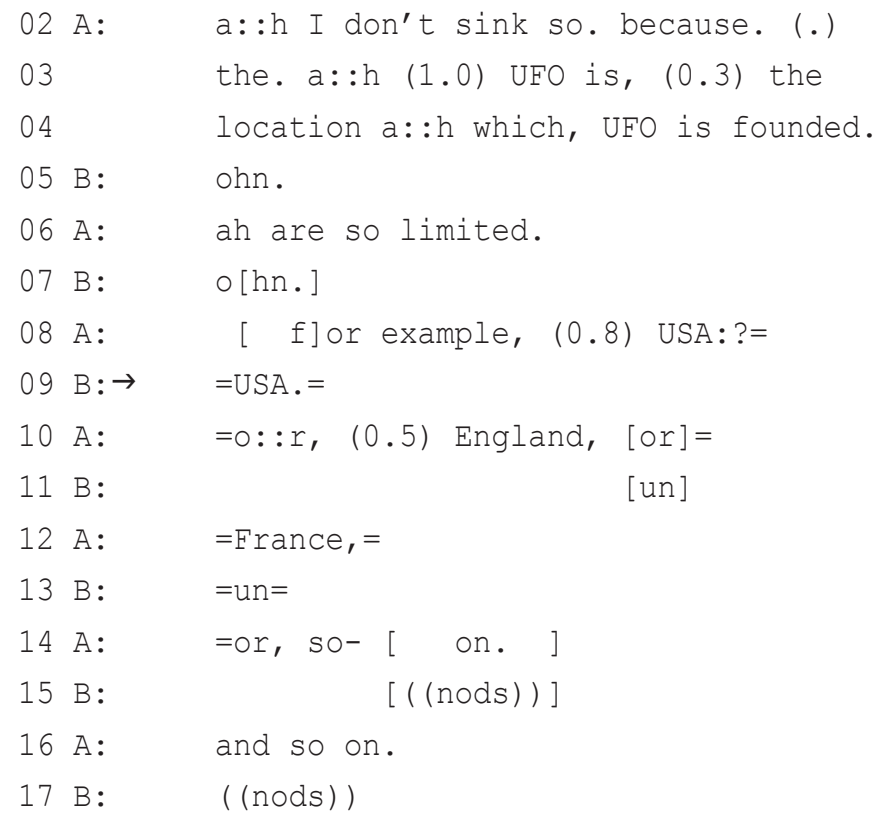

In this example the receipt-through-repetition comes in line 9. In line 2 speaker A produces a disagreement followed by an account in lines 3 to 6 (UFOs are only found in certain "limited" places). Speaker B aligns to this turn as a recipient, producing minimal receipt tokens (lines 5 and 7) after A's intonationally complete term increments. Speaker A then furthers his account by initiating a list of examples, beginning with USA (line 8). Elongation of the final vowel sound and upward intonation indicate that this is the first of a list-in-progress. 
It is at this point that $\mathrm{B}$ repeats the word USA, to enact receipt and indicate to $A$ that he is following. This receipt-through-repetition facilitates the flow of the conversation, signaling to A that B has comprehended the first element of the list and prompting A to continue with his turn. There is no gap between the repeated token and speaker A's next turn, and the subsequent turn increments are produced in rapid succession, as evidenced by the latching and overlap in lines 8-14. As A's list grows longer, the strength of speaker B's receipt tokens decreases from a repetition of the word USA (line 9) to minimal receipts in Japanese un (lines 11 and 13) and mere nods (lines 15 and 17).

A similar case can be found several turns later in the same conversation in which A reprises his argument that UFOs are only found in 'limited' places. Again, B is acting as the recipient.

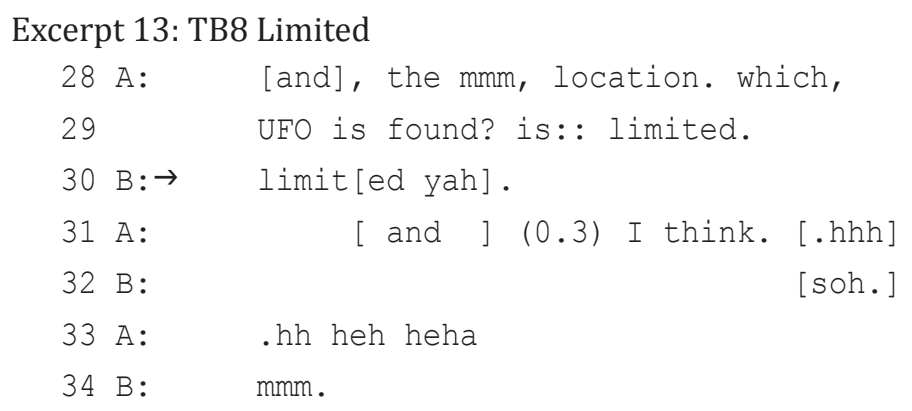

What exactly A means by 'limited' is unclear, at least to us as analysts. In excerpt 12 he seems to be saying that he does not believe aliens have visited Earth because reported UFO sightings generally only happen in 'a narrow subset' of countries (i.e., Western nations). On the other hand, he could also be using 'limited' to mean 'restricted' referring to the notion that UFO sightings are often reported near classified military bases. The point is that A's usage of the word 'limited' is potentially problematic, and there is evidence in lines 28-29 to suggest that he himself sees it this way. This turn is remarkably similar to lines 3-6 in excerpt 10, and so A's "second doing," along with the upwards intonation on 'found' and the elongation of 'is' in line 29 both indicate he is initiating forward-oriented repair (Carroll, 2004) in the form of a word search that ends in the same word 'limited.' This seems to indicate that although A himself is not satisfied with the word he has chosen, it is the most appropriate lexical item available to him at that moment. 
Be that as it may, B's turn in line 30 is anything but hesitant. Speaker B accompanies his receipt-through-repetition with an acknowledgement token ("yah"), demonstrating to A that he claims to understand what A means and allowing him to continue speaking. And indeed this is what A does, overlapping his ongoing turn in line 31 with B's turn. It would seem that the first half of B's receipt-through-repetition is sufficient for A to recognize the go-ahead signal. The repetition of the key element 'limited' displays that B understands the term and signals to A that no further explanation is needed.

Whether it is part of a list or a potentially problematic term, it seems that the turn prior to a receipt-through-repetition is sometimes designed to invite uptake from the listener. Let's examine another instance where the repeated element of the turn is offered as an example. In this conversation, A has just told B that he is sometimes attracted to older women.

Excerpt 14: Fnds2 Kuroki Hitomi

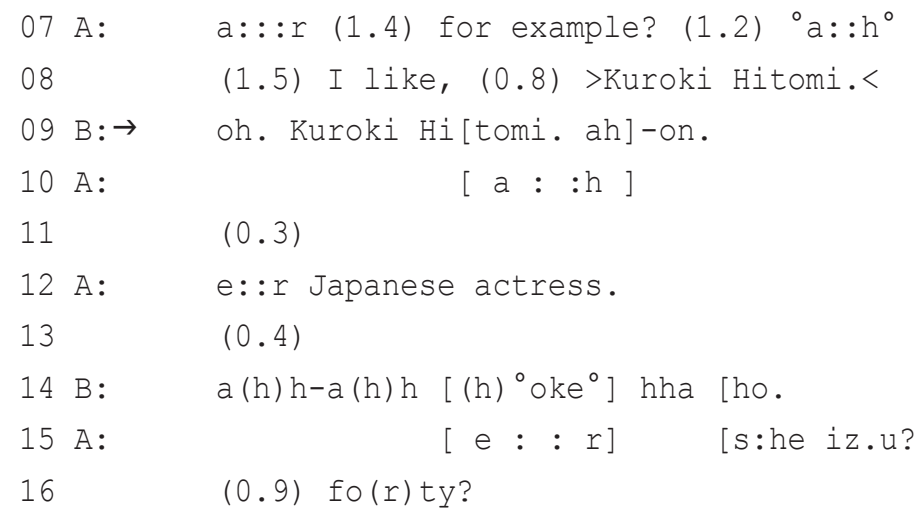

Here the repeated element is the name of a middle-aged actress who is known for her beauty. The way the initial turn in the sequence is produced has a number of features in common with the earlier excerpts, including turn-internal pauses, elongations, and fillers prior to the eventual utterance of a key turn-final element. In this case it may indicate a word search, as did 'limited' in excerpt 12 , or it could be designedly reticent, given that the youthful speaker is admitting he admires an older woman. What is important is that $\mathrm{A}$ is introducing a new topic to the conversation, one that $\mathrm{B}$ should be expected to either (1) recognize, or (2) clarify, such as by asking, "Who's that?" Without this sort of feedback, A would have to proceed with the topic in a different way, perhaps with a try-marker (Sacks \& Schegloff, 
1979) or by initiating a confirmation check.

As it happens, B does recognize the reference and expresses this in line 9 with receipt-through-repetition in combination with a turn-initial changeof-state token, oh. Heritage (1984) found that such markers demonstrate a change of epistemological states. That is, by saying ' $o h$ ' B is claiming that he has achieved a new knowledge state: he did not know that A likes Kuroki Hitomi, but now he does. He follows this with repetition as receipt, specifying the key element of the news and completing his turn with a further acknowledgement token in Japanese ('ah-on'), which may also project agreement (See Ikeda 2007 for discussion of Japanese change-of-state tokens).

As was also the case in excerpts 12 and 13, speaker A's next turn comes quickly, overlapping speaker B's receipt in line 10. Self-selection at this point is a turn-competitive bid by $\mathrm{A}$, and again $\mathrm{B}$ aligns as recipient by waiting in line 11 and listening while A produces a turn increment in line $12 .{ }^{6}$

\section{Repeat, Receipt, and Repair}

So far we have noted that doing receipt-through-repetition specifies some element of the prior turn that the listener claims to understand, and that the teller has designed to be somehow 'worth understanding' due to its projected import for the topic-in-progress. The next case demonstrates some of the difficulty experienced in determining whether or not an instance of repetition is intended as receipt-an issue for the participants in real time as much as it is for us as analysts (see Schegloff, 1996b).

Here the same participants from excerpt 14 are discussing whether age makes a difference in a relationship, and A, claiming an extended turn as the primary speaker, begins an account of why he thinks a younger man can love an older woman. While our analysis is only concerned with the first part of this account, the upshot of A's full utterance is that "relationships don't necessarily work out even when the couple is the same age."

Excerpt 15: Fnds2 Wo- wimmen

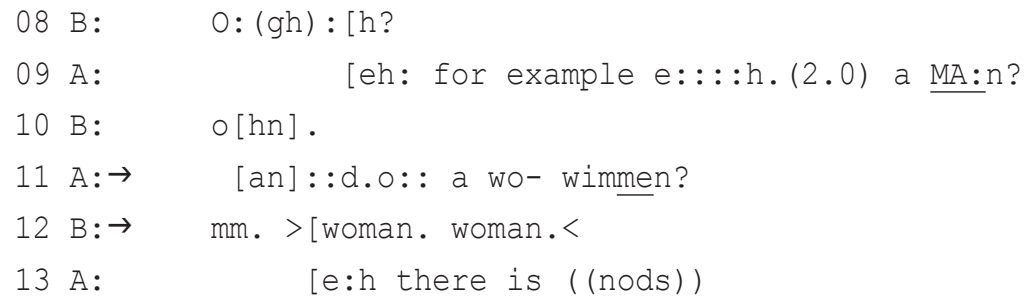




$\begin{array}{ll}14 & \text { there are two. >eh< and? (.) } \\ 15 & \text { a:h they are? same. age. } \\ 16 & (0.5) \\ 17 \mathrm{~A}: & {[(\mathrm{l})]} \\ 18 \mathrm{~B}: & {[0: \mathrm{h} .] \mathrm{oh} . \mathrm{oh} \text { okeh. }}\end{array}$

As in several of the earlier excerpts, just prior to the point at which the listener provides the receipt-through-repetition, the primary speaker is conducting forward-oriented repair. Typical of such word-searches, the first turn in the sequence (line 9) displays uncertainty with a pause, fillers, and elongations, as well as rising intonation. Speaker B reacts to A's rising intonation with a minimal response in line 10 and A continues his turn in overlap (line 11), producing a vowel-marked token ${ }^{7}$ ('and.o') with considerable elongation at an incomplete point in the turn, which projects a yet-to-appear trouble source. Speaker A finally produces the token he was searching for by the end of line 11, first in what is audibly on the way to the singular 'a woman' and then in the plural 'women.' Since it completes the second part of a standardized relational pair (Sacks, 1972) and is grammatically typerelated to 'a man' in line 9, A's first token was actually correct, but for some reason he performs a cut-off before the token is complete, rapidly enacting backwards-oriented self-repair by replacing it with 'women,' such that the token sounds something like 'wo-wimmen.' Note that while A has 'repaired' his utterance, it wasn't really 'broken' in the first place, and further repair becomes relevant as a possible next action.

However in fact what B does next at the start of line 12 is a minimal response token 'mm,' which may have been triggered by the rising intonation at the end of line 11, as it was in lines 9 and 10. Speaker B then follows this with a swift double utterance of the correct form of the trouble source, woman. It is difficult to know whether B intended this as correction or as receipt of A's aborted first try, but by examining the third turn (line 13) we can say that A initially treats it as receipt by carrying on with the sentence, just as the speakers did in the earlier excerpts we examined. Only at the end of his turn does A address the possibility that B was correcting him, by giving a nod, which could be interpreted as either an acknowledgement of the other-repair, or perhaps 'receipt-of-receipt.' At any rate, this seems to be one of the kinds of post-overlapped responses that Jefferson $(1993$, p. 3) refers to as "attention on the way to something else," as it gives only the barest of acknowledgements before continuing on with the remainder of the turn. 
Svennevig (2004) notes that such receipts after 'broken starts' may help the primary-speaker to produce the turn-in-progress by displaying the listener's current interpretation of what is being said, which ultimately accomplishes communication. By formulating the repeated turn as a receipt rather than a direct repair initiator, the recipient accomplishes 'embedded correction' (Jefferson, 1987) of the kind that is regularly used by teachers and expert speakers. Svennevig claims that such receipts make relevant the "linguistic asymmetry of the parties, and constitute a practice whereby native speakers display their construal of [an imprecise] utterance" (2004, p. 504). Our study has confirmed that the same sort of practice can occur between 'nonnatives,' suggesting that the difference is more about relative linguistic expertise than about 'nativeness' per se.

Our final excerpt is an extended sequence of talk in which several instances of repetition appear. A close examination will reveal the ways that this interactional practice not only establishes recipiency but also enables the recipient to take a more active role in co-completing the telling. Taken from the same data set as the previous excerpt, B is attempting to express his opinion concerning age difference in relationships. At this point in the talk, B has stated that relationships with a significant age gap will be unsuccessful, and he is giving examples of some famously mismatched Japanese couples to illustrate his position.

Excerpt 16: Fnds2 Break break

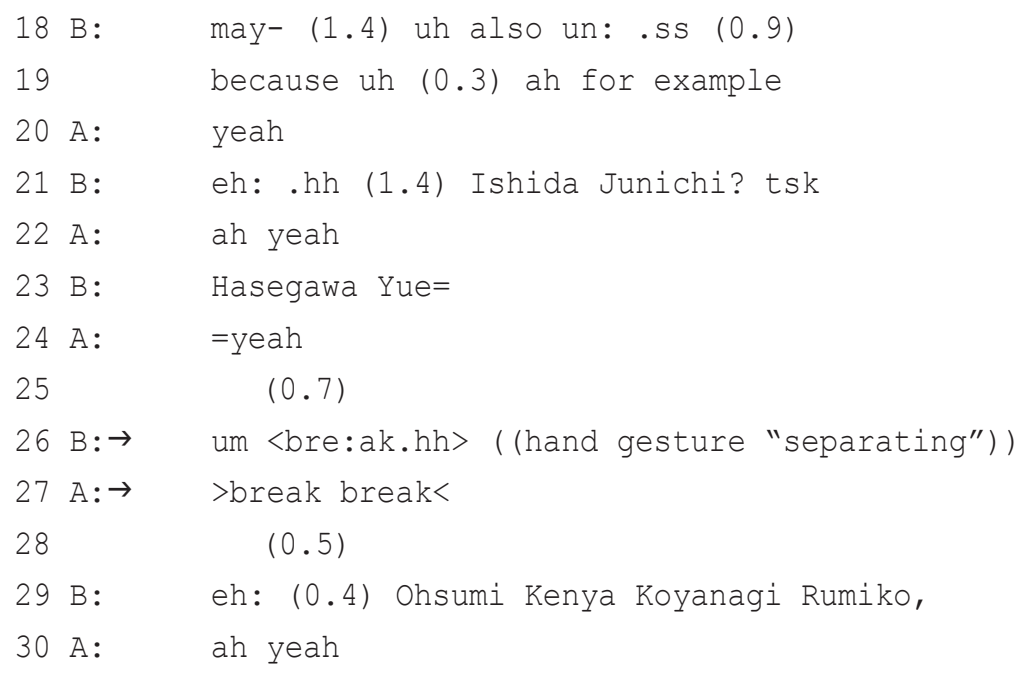




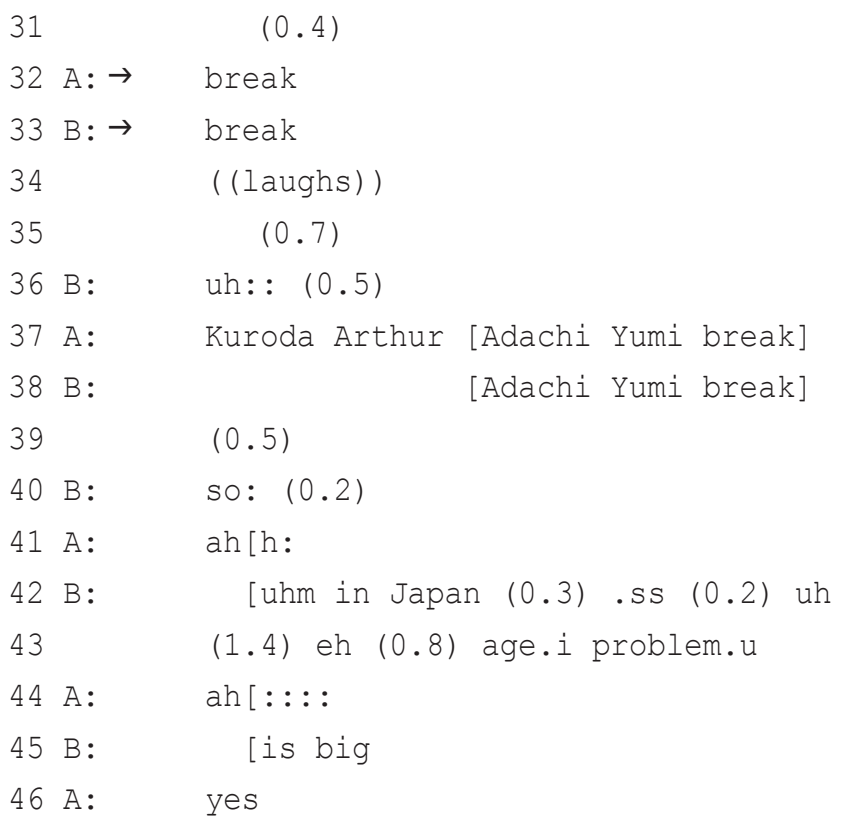

This sequence is similar to excerpt 12 (USA) in that they both involve listener repetition in the co-construction of a three-part list. In conversation, recipient feedback through repetition seems to be an integral element of expressing lists, which are regularly constructed over multiple turns even by expert speakers of English (Jefferson, 1990).

Speaker B puts forward the names of the first couple (lines 21 and 23), and Speaker A provides a minimal receipt token ('yeah') for each. Speaker $\mathrm{B}$ then produces the word break (line 26) in a somewhat hesitant manner. Beginning with the noticeable gap in line 25 , there is ample evidence to suggest that B appears uncertain about whether the word break is an acceptable English term to describe the breaking up of a couple: the turn-initial filler, the measured and deliberate way in which he produces the term itself, the mid-word vowel elongation, the turn-final breathing-out, and the cooccurring hand gesture all imply that B is designing the turn as potentially problematic. Even so, A provides immediate acceptance of the term by rapidly repeating it twice in line 27.

It is important to note that the English word break does exist as a loanword in Japanese and can be used to describe a break-up. These participants have undoubtedly brought this L1 lexical knowledge with them to the conversa- 
tion. Together they suggest three examples of couples who have broken up, each following a basic proto-grammatical pattern that could be schematized as [Name1 Name2 break], but appears to be understood by the interactants themselves as [Name1 and Name2 broke up].

Although somewhat slower ${ }^{8}$ than those in other excerpts we have examined, B completes the sequence by continuing the list in the third turn (line 29 ) self-selecting to name another couple as the next example. In line 30 , A gives a minimal go-ahead response and briefly waits for $B$ to continue in line 31 . However, when B does not complete the turn in a timely manner, A self-selects to produce the word break according to the same form that $\mathrm{B}$ used in lines 21-26, and this time it is B who repeats the key element in line 33. However, repetition in this case would not be an accurate description: given his slower speaking pace it is more likely that B is simply completing the turn he began in line 29 and A was able to project the appropriate turn ending and produce it before B. Therefore we do not consider lines 32 and 33 as a case of receipt-through-repetition, but instead a co-completion (Lerner, 2002).

At this point the participants switch roles: A, who was mainly the listener, becomes the primary speaker, while $B$, who has been giving the examples, becomes the recipient. In line 37, Speaker A then proposes a third pair of names to add to the list, allowing B to chorally co-complete the turn (Lerner, 2002) as they name the second partner and produce the word break once again, but in unison.

This excerpt reveals how even speakers with limited knowledge of the L2 can engage in conversation without letting their linguistic limitations get in the way. They are capable of co-constructing a conversational sequence even when they themselves have questioned whether their word usage is appropriate. Once the speaker has received confirmation that the listener has accepted the term-in-use, he or she can continue his turn, and even cocomplete it with the listener.

\section{Discussion and Conclusion}

By this point, some readers are no doubt beginning to wonder why we need to go into so much detail about what seems like such an insignificant thing. In response to such a claim, we would point out that anatomists have documented the tiniest aspects of the human body, naming the parts and describing their functions. As language professionals, we believe that we should be equally interested in the focus of our work, which in this case is 
unscripted conversation. The CA approach challenges us to look at mundane talk as a series of socio-pragmatic actions, and to develop an empirical description of the practices of which it consists.

This paper has documented one important interactional strategy available to novice speakers of English. A primary-speaker introduces a new element to the conversation during a telling or an informing. Since it is the initial appearance of this element, recipient recognition becomes relevant as a next-turn action. Sometimes the primary-speaker designs the newsworthy element as potentially problematic but important for the ongoing talk, yet the listener repeats the token in a faster, less problematic manner, often combined with some embodied display of agreement or acknowledgement such as a nod. This receipt-through-repetition provides a brief uptake that signals the primary speaker to continue with the turn-in-progress. In this respect the second turn is similar to other receipt tokens in that it does not imply that the recipient is going to take an extended turn.

Yet this form of receipt does more than just that. It displays a recipient claim to specific comprehension of some key element in the prior turn, allowing the primary-speaker to continue, and to go on using the repeated element in subsequent talk, having established intersubjectivity in this temporal and sequential context. Therefore, receipt-through-repetition is an important interactional resource L2 learners can use when negotiating meaning.

While these conversations were all taken from peer-matched oral proficiency tests, there is little in the data to indicate that the practice of repeating a prior-turn segment to enact receipt is limited only to test-talk. Indeed, its use in several of the situations we have looked at would seem to indicate that the students are orienting to the negotiation of meaning. The data in excerpt 5 for example, eventually leads to the negotiation of the word "Germany," and we have noted the students' use of embedded correction in wo-wimmen (excerpt 15). By acknowledging a specific token, receipt-through-repetition claims understanding of it at that point, and therefore frees the primaryspeaker to progress the topic further. It therefore plays an important role in encouraging second language learners to experiment with language and encourage communication.

One of the authors' initial observations as we discussed the data was that these repeats somehow "sounded Japanese" to us, as if the participants were carrying over Japanese recipiency practices into their L2. Certainly the work by Clancy et al. (1996) suggests that the practice is far more frequent in Japanese than in English. However, the same study also measures the number of 
receipts-through-repetition among expert speakers of English so it is obviously also a practice that can be used by so-called 'natives.' Therefore the beginning learners we studied are in fact able to make use of a native-like interactional practice. Our original impression may have less to do with the fact that the participants are Japanese, and more to do with the fact that they are novice speakers of English, and are therefore participating in conversation that requires specific receipt tokens more regularly.

Although the general CA aesthetic emphasizes similarities rather than differences, Wong (2000) notes that novice speakers of English do not use same-turn repetitions to accomplish the resumption of some prior thread of talk after a parenthetical sequence in the way that expert speakers do. She suggests that this skill is something that might be beyond their linguistic proficiency. The kind of repetition that we have looked at in this paper may be the flip side to this argument. Although expert speakers can also use repetition to demonstrate recipiency, they do not seem to do so with the same frequency as the novice participants in the data we examined. Again, this might be partly because there are fewer occasions when an expert speaker does not know a word, so they do not have to produce it in a way that receives repetition.

Given that the initial turn in the sequence often contains some sort of 'designedly unsure' or 'response worthy' item, it is perhaps somewhat natural that novice speakers will need to produce more of these sorts of turns, both due to their limited L2 repertoire and the fact that they are designing the turn for an audience who may not understand. Recipients, in turn, will respond to this with repetition in accordance with the practice we have outlined. While the current study has focused on novice-novice data, Svennevig (2004) has suggested that other-repetition is also often used in novice-expert pairs, such as when instructors repeat a word used by a learner in order to encourage him or her to continue talking.

In fact, in a recent issue of the JALT Journal, Sato (2007) has suggested that novice learners of English use this receipt practice more when speaking with experts. Although the current study has not aimed to measure frequencies, its fine-grained analysis may help to reveal some of the reasons behind this phenomenon, and we would suggest that this is more likely to occur because the speakers see a perceived need to make specific their turn-byturn intersubjective understanding.

While too many of these sorts of repetitions might make the talk seem unnatural, it did not seem to hinder the novice speakers in our data set. If anything, it seemed to help keep the conversation flowing. This suggests that next-turn other-repetition, particularly of problematic words, may help 
learners to facilitate communication by providing the speaker with explicit feedback on their moment-to-moment understanding. Teachers and textbook writers would do well to make sure that examples of this practice appear in second language learning resources. Research into shadowing (e.g., Murphey, 2001) has found that the practice of repeating and revoicing turnfinal items may in fact help recipients to better comprehend the speaker's speech. Although the participants in this study were not specifically taught shadowing in the classes that led up to these oral proficiency tests, it is possible that some of the students independently developed and made use of a variety of this communication technique.

It is hoped the current analysis will help language teachers appreciate that students possess existing interactional competencies which can enable them to participate in classroom activities and regulate primary-speaker utterances by the way they respond to them. Close attention to the sequential unfolding of this L2 talk has outlined one way that novice speakers display momentary turn-by-turn understandings. Receipt tokens, such as repetition of prior turn segments, provide important cues for the primary speaker, and are therefore consequential for the way that the remainder of a turnin-progress is designed. Language use and language acquisition are both socially accomplished, and so the best place to look for evidence of learning is in micro-social actions, such as receipt. When all is said and done, in order to make judgments about internally achieved notions like 'learning' or 'cognition,' teachers, testers, and analysts have only what the participants themselves have to go on-external, real-time claims to understanding in conversation. The interactional practice of receipt-through-repetition is one resource for making such judgments.

Tim Greer is an associate professor at Kobe University. His doctoral dissertation uses Conversation Analysis and ethnography to examine ways that multiethnic Japanese teenagers accomplish aspects of their identity in bilingual interaction. He is currently researching naturally-occurring interaction between novice and expert speakers of English.

Vivian Bussinguer is in the Doctoral program at Kobe University. Her dissertation focuses on immigrant children's L1 maintenance and L2 acquisition. She is also interested in bilingualism, heritage language, language loss, and minority language education. 
Jeff Butterfield completed a Master's degree at Kobe University in 2007. In addition to his interests in Conversation Analysis and language teaching, he is also researching the textbook issue and its effects on Sino-Japanese relations.

Agnes Mischinger completed a Master's degree with the School of Cultural Studies and Human Sciences, Kobe University in 2007, specializing in nonverbal communication. Her thesis looked at acculturation and adjustment among foreigners living in Japan.

\section{References}

Carroll, D. (2004). Restarts in novice turn beginnings: Disfluencies or interactional achievements? In R. Gardner \& J. Wagner (Eds.), Second language conversations (pp. 201-220). London: Continuum.

Clancy, P. M., Thompson, S. A., Suzuki, R., \& Tao, H. (1996). The conversational use of reactive tokens in English, Japanese, and Mandarin. Journal of Pragmatics, 26, 355-387.

Firth, A., \& Wagner, J. (1997). On discourse, communication and (some) fundamental concepts in SLA research. The Modern Language Journal, 81, 285-300.

Gardner, R. (1997). The conversation object mm: A weak and variable acknowledging token. Research on Language and Social Interaction, 30(2), 131-156.

Gardner, R. (1998). Between speaking and listening: The vocalisation of understandings. Applied Linguistics, 19(2), 204-224.

Gardner, R. (2001). When listeners talk: Response tokens and listener stance. Amsterdam-Philadelphia: John Benjamins.

Gardner, R., \& Wagner, J. (2004). Second language conversations. London: Continuum.

Goodwin, C. (1986). Between and within: Alternative sequential treatments of continuers and assessments. Human Studies, 9, 205-217.

Greer, T. (2007) Accomplishing identity in interaction: Codeswitching practices among a group of multiethnic Japanese teenagers. Unpublished doctoral thesis, University of Southern Queensland, Australia. Available online at http://adt.caul. edu.au

Hellermann, J. (2003). The interactive work of prosody in the IRF exchange: Teacher repetition in feedback moves. Language in Society, 32, 79-104.

Heritage, J. (1984). A change-of-state token and aspects of its sequential placement. In J. M. Atkinson \& J. Heritage (Eds.), Structures of social action: Studies in conversation analysis. (pp. 299-345). New York: Cambridge University Press. 
Ikeda, K. (2007). The change-of-state token a in Japanese language proficiency interviews. Paper presented at the 6th Annual JALT Pan-SIG Conference, Sendai, Japan. Available online at http://www.jalt.org/pansig/2007/HTML/Ikeda.htm

Jefferson, G. (1985). Notes on a systematic deployment of the acknowledgement tokens 'Yeah' and 'Mmhm'. Papers in Linguistics, 17(2), 197-216.

Jefferson, G. (1987). On exposed and embedded correction in conversation. In G. Button \& J. R. E. Lee (Eds.), Talk and social organization. (pp. 86-100). Clevedon: Multilingual Matters.

Jefferson, G. (1990). List construction as a task and resource. In G. Psathas (Ed.), Interaction competence (pp. 63-92). New York: Irvington.

Jefferson, G. (1993). Caveat speaker: Preliminary notes on recipient topic-shift implicature. Research on Language and Social Interaction, 26(1), 1-30.

Kendon, A. (1967). Some functions of gaze directions in social interaction. Acta psychologica, 26, 22-63.

Lerner, G. (2002). Turn sharing: The choral co-production of talk-in-interaction. In C. Ford \& B. Fox \& S. Thompson (Eds.), The language of turn and sequence (pp. 225-256.). Oxford: Oxford University Press.

Markee, N., \& Kasper, G. (2004). Classroom talks: An introduction. The Modern Language Journal, 88(4), 491-500.

Maynard, S. (1989). Japanese conversation: Self-contextualization through structure and interactional management. Norwood, NJ: Ablex.

Murphey, T. (2001). Exploring conversational shadowing. Language Teacher Research 5(2) 128-155.

Pomerantz, A. (1984). Agreeing and disagreeing with assessments: Some features of preferred/ dispreferred turn shapes. In J. M. Atkinson \& J. Heritage (Eds.), Structures of social action: Studies in conversation analysis (pp. 57-101). Cambridge: Cambridge University Press.

Richards, K., \& Seedhouse, P. (Eds.). (2005). Applying conversation analysis. London: Palgrave Macmillan.

Sacks, H. (1972). On the analyzability of stories by children. In J. Gumperz \& D. Hymes (Eds.), Directions in sociolinguistics (pp. 325-345). New York: Holt, Rinehart and Winston.

Sacks, H. (1984). On doing "being ordinary". In J. M. Atkinson \& J. Heritage (Eds.), Structures of social action: Studies in conversation analysis (pp. 513-529). Cambridge: Cambridge University Press. 
Sacks, H., \& Schegloff, E. (1979). Two preferences in the organization of reference to persons in conversation and their interaction. In G. Psathas (Ed.), Everyday language: Studies in ethnomethodology (pp. 15-21). New York: Irvington.

Sacks, H., Schegloff, E., \& Jefferson, G. (1974). A simplest systematics for the organization of turn-taking in conversation. Language, 50(4), 696-735.

Sato, M. (2007). Social relationships in conversational interaction: A comparison of learner-learner and learner-NS dyads. JALT Journal, 29(2), 183-208.

Schegloff, E. (1982). Discourse as an interactional achievement: Some uses of 'uh huh' and other things that come between sentences. In D. Tannen (Ed.), Analyzing discourse: Text and talk. Washington DC: Georgetown University Press.

Schegloff, E. (1996a). Confirming allusions: Towards an empirical account of action. American Journal of Sociology, 104, 161-216.

Schegloff, E. (1996b). Issues of relevance for discourse analysis: Contingency in action, interaction, and co-participant context. In E. Hovy \& D. Scott (Eds.), Computational and conversational discourse: Burning issues-an interdisciplinary account (pp. 3-38). Heidelberg: Springer.

Schegloff, E. (2007). Sequence organization in interaction: A primer in conversation analysis. Cambridge: Cambridge University Press.

Schegloff, E., Jefferson, G., \& Sacks, H. (1977). The preference for self-correction in the organization of repair in conversation. Language, 53(2), 361-382.

Schegloff, E., Koshik, I., Jacoby, S., \& Olsher, D. (2002). Conversation analysis and applied linguistics. Annual Review of Applied Linguistics, 22, 3-31.

Seedhouse, P. (2005). Conversation analysis and language learning. Language Teaching, 38(4), 165-187.

Stivers, T. (2004). "No, no, no" and other types of multiple sayings in social interaction. Human Communication Research, 30(2), 260-293.

Svennevig, J. (2004). Other-repetition as display of hearing, understanding and emotional stance. Discourse Studies, 6, 489-516.

ten Have, P. (1999). Doing conversation analysis: A practical guide. London: Sage.

Wagner, J., \& Firth, A. (2007). Second/foreign language learning as a social accomplishment: Elaborations on a reconceptualized SLA. The Modern Language Journal, 91(Focus issue), 800-819.

Wong, J. (2000). Repetition in conversation: A look at "first and second sayings". Research on Language and Social Interaction, 33(4), 407-424.

Yngve, V. (1970). On getting a word in edgewise. Papers from the sixth regional meeting, Chicago Linguistic Society (pp. 567-577). Chicago, IL: Chicago Linguistic Society. 


\section{Appendix A}

\section{Transcription conventions}

\section{SIMULTANEOUS UTTERANCES}

huh [ oh ] I see Left square brackets mark the start of overlapping talk [what ] Right square brackets mark the end of an overlap

\section{CONTIGUOUS UTTERANCES}

$=\quad$ Equal signs indicate that:

a) Turn continues at the next identical symbol on the next line, or

b) Talk is latched; that is, there is no interval between the end of prior turn and the start of next turn

INTERVALS WITHIN AND BETWEEN UTTERANCES

$(0.4)$

(.)
Numerals in parentheses mark silence, in tenths of a second

A period in parentheses indicates a micropause (less than $0.1 \mathrm{sec}$ )

\section{CHARACTERISTICS OF SPEECH DELIVERY}

hhh hee hah

$g(h)$ et ou (h)t

. $\mathrm{hh}$

hh

mine

found? is

yes.

so,

$\mathrm{HUH}$

${ }^{\circ}$ thanks ${ }^{\circ}$

$>$ limited $<$ indicate laughter or breathiness

used in parentheses when the laughter occurs within a word

indicates audible inhalation

indicates audible exhalation

Underlining indicates marked stress

A question mark indicates rising intonation

A period indicates falling intonation

A comma indicates low-rising intonation, suggesting continuation

Capitals indicate increased loudness

Degree signs indicate decreased volume

Inward-facing indents embed talk which is faster than 


\begin{tabular}{|c|c|}
\hline \multicolumn{2}{|c|}{ the surrounding speech } \\
\hline$<$ break $>$ & $\begin{array}{l}\text { Outward-facing indents embed talk that is slower than } \\
\text { the surrounding speech }\end{array}$ \\
\hline go: : : d & $\begin{array}{l}\text { One or more colons indicate lengthening of the } \\
\text { preceding sound. Each additional colon represents a } \\
\text { lengthening of one beat }\end{array}$ \\
\hline wo- wimmen & $\begin{array}{l}\text { A single hyphen indicates an abrupt cut-off, with level } \\
\text { pitch }\end{array}$ \\
\hline \multicolumn{2}{|c|}{ COMMENTARY IN THE TRANSCRIPT } \\
\hline ( (hand clap)) & $\begin{array}{l}\text { Double parentheses indicate transcriber's comments, } \\
\text { including description of non-verbal behaviour }\end{array}$ \\
\hline the (park) & Single parentheses indicate an uncertain transcription \\
\hline \multicolumn{2}{|c|}{ OTHER TRANSCRIPTION SYMBOLS } \\
\hline$\rightarrow$ & $\begin{array}{l}\text { An arrow in the transcript margin draws attention to a } \\
\text { particular phenomenon the analyst wishes to discuss }\end{array}$ \\
\hline \multicolumn{2}{|l|}{ Appendix B } \\
\hline \multicolumn{2}{|c|}{ A Glossary of CA Terms Used in this Paper } \\
\hline Intersubjectivity & $\begin{array}{l}\text { The process by which interactants establish shared } \\
\text { meanings and understandings in conversation. }\end{array}$ \\
\hline Receipt tokens & $\begin{array}{l}\text { A short utterance that indicates a listener is follow- } \\
\text { ing some prior element of a primary speaker's talk. } \\
\text { Typical English examples might include "uhuh," } \\
\text { "hmm" or "yeah." }\end{array}$ \\
\hline
\end{tabular}




\begin{tabular}{|c|c|}
\hline Repair & $\begin{array}{l}\text { Any of a number of interactional practices speakers } \\
\text { use to deal with trouble in talk. Backward-oriented } \\
\text { repair seeks to rectify some mistake or problem } \\
\text { that has already appeared in the talk, e.g., } \\
\text { "now (1.1) I don't study (0.4) dent- } \\
\text { about }(0.4) \text { dentistry," } \\
\text { while forward-oriented repair, such as a word } \\
\text { search sequence, addresses trouble that has yet to } \\
\text { be made explicit in the turn, e.g., } \\
\text { "I live i: } n \text {, (0.7) um (2.3) eas- um? } \\
\quad(0.5) \text { eastern part of Sapporo." } \\
\text { Repair can be initiated and/or completed either by } \\
\text { current-speaker (self-repair) and/or next-speaker } \\
\text { (other-repair). For further details, see Schegloff, } \\
\text { Jefferson and Sacks (1977). }\end{array}$ \\
\hline Self-selection & $\begin{array}{l}\text { A turn-taking practice in which the speaker elects } \\
\text { to speak next (or to continue speaking), as opposed } \\
\text { to other-selection, which often happens through } \\
\text { questions or other sequence initiating actions. See } \\
\text { Sacks, Schegloff, and Jefferson (1974). }\end{array}$ \\
\hline Trouble source & $\begin{array}{l}\text { Any part of a turn that the participants orient to } \\
\text { as "in need of repair." This may be, for instance, } \\
\text { a grammatical error, a mistaken referent (such } \\
\text { as calling someone by the wrong name), a less- } \\
\text { than-true statement, or indeed anything that the } \\
\text { speakers treat as repairable. For example, in the } \\
\text { following sequence, the trouble source is "much": } \\
\text { A: much snow. in Kitami. } \\
\text { [ }(0.6) \\
\text { D: [( (moves head toward A)) ] } \\
\text { A: much snow. } \\
\text { D: noless snow. }\end{array}$ \\
\hline $\begin{array}{l}\text { Turn- } \\
\text { competitive bid }\end{array}$ & $\begin{array}{l}\text { When two or more speakers attempt to start speak- } \\
\text { ing at the same time. }\end{array}$ \\
\hline
\end{tabular}




\section{Turn increment}

\section{Endnotes}

1. The current study does not focus on native speakers of English, but transcripts from other researchers (Clancy et al., 1996; Gardner, 2001; Schegloff, 1996a, 1996b) lead us to believe that English experts also use repetition to accomplish these actions.

2. Italicized terms are explained in further detail in the glossary (Appen$\operatorname{dix}$ B).

3. In this case the speaker is also able to specify the target of the search in L1. For further discussion of word searches in bilingual interaction, see Greer (2007).

4. Note that in this case the candidate repair is not actually correct, but the fact that the participants treat it as correct at this point in the talk is all that matters in terms of the understanding they are trying to arrive at. In fact, just after this excerpt, the students negotiate the word further, and eventually C offers "Germany" as an alternate.

5. Here the speaker is talking about his desire to one day buy a farm. Therefore his utterance here should be understood as something like, "I will buy some farmland in Hokkaido." The fact that the turn is ungrammatical and includes some inaccurately used vocabulary only serves to point out that listener B is acknowledging only one element of the turnin-progress, the word 'Hokkaido.'

6. It is interesting to note that A's turn here is a try-marker, which would normally indicate that he believes $B$ does not recognize the referent he has used, despite the fact that $\mathrm{B}$ has made a bold claim to such recognition in his prior turn. The fact that this conversation is happening as part of an oral English proficiency test may partly account for A's action here, either as a bid to include the English-speaking tester (who is copresent but not actively participating in the conversation), or as part of a normative practice in EFL classes by which non-English referents and cultural artifacts are elucidated when first used. There is evidence in the transcript, however, to suggest that B finds A's clarification superfluous. After a noticeable gap in line 13, B responds with laughter, a further on-record receipt token ('okay') and the multiple saying of the Japanese 
receipt token 'ah.' Stivers (2004) notes that such multiple sayings occur in sequential environments in which the primary speaker has provided too much information. Their occurrence at this point in the talk demonstrates that, for B at least, the receipt-through-repetition should have been a sufficient signal to A that he understood the referent in question.

7. See Carroll (2004) for further discussion on how Japanese learners of English use vowel-marking in forward repair.

8. This difference in pace could be due to the participant himself. This student generally speaks relatively slowly throughout the complete conversation. 